'Departamento de Neurología y Psiquiatría Clínica Alemana de Santiago-Universidad del Desarrollo. Santiago, Chile. 2Departamento de Ciencias Neurológicas, Facultad de Medicina, Universidad de Chile. Santiago, Chile. ${ }^{3}$ Instituto Milenio de

Neurociencias Biomedicas (BNI), Facultad de Medicina, Universidad de Chile. Santiago, Chile.

${ }^{4}$ Departamento de Medicina Interna Clínica Alemana de Santiago-Universidad del Desarrollo. Santiago, Chile. ${ }^{a} \mathrm{PhD}$. ${ }^{\mathrm{b}} \mathrm{MsC}$.

El presente caso clínico no recibió apoyo financiero.

Los autores no declaran conflicto de interés.

Recibido el 26 de junio de 2017, aceptado el 10 de octubre de

2017

Correspondencia a: Dra. Paula Jara Avenida Vitacura 5951. Santiago, Chile. pjaram@alemana.cl

\section{Polirradiculoneuritis aguda asociada a infección por Virus Herpes Humano 7 en un paciente adulto inmunocompetente}

\author{
PAULA JARA ${ }^{1}$, JOSÉ MANUEL MATAMALA ${ }^{1,2,3, a}$, \\ RENATO VERDUGO ${ }^{1, b}$, LUIS THOMPSON ${ }^{4}$
}

\section{Acute polyradiculoneuropathy associated with human Herpes Virus 7 in an immuno- competent patient. Case report}

Human herpes virus 7 (HHV-7) is a cause of encephalitis, meningitis and myeloradiculoneuropathy in adults who are immunocompetent or with immunosuppression. The involvement of the peripheral nervous system is always associated with myelitis. We report a case of acute polyradiculoneuropathy due to $H H V-7$, without involvement of central nervous system, in an immunocompetent patient. A 35-years-old man complained of lumbar pain radiating to both buttocks. On examination muscle strength and tendon reflexes were normal. He had asymmetric pinprick and light touch saddle hypoesthesia and also in the perineal region, dorsum and lateral aspect of the left foot. Magnetic resonance imaging showed mild thickening and contrast enhancement of cauda equina nerve roots. Polymerase chain reaction performed on cerebrospinal fluid was positive for HVV-7. Other inflammatory, infectious and neoplastic etiologies were ruled out. Lumbar pain and hypoesthesia improved progressively and neurological examination was normal after one month. He did not receive antiviral therapy.

(Rev Med Chile 2017; 145: 1218-1221)

Key words: Encephalitis; Herpesvirus 7, Human; Meningitis; Myelitis; Polyradiculoneuropathy.
E 1 Virus Herpes Humano 7 (VHH-7), es un virus DNA de doble cadena, neurotrópico y linfotrópico, que pertenece a la subfamilia de los herpes virus. Está presente en 96 a 100\% de la población adulta, el $70 \%$ de los casos se infectan durante los primeros 5 años de vida y el $30 \%$ restante más tardíamente. Es transmitido por vía oral y posterior a la infección primaria se mantiene latente en los linfocitos T CD4+ y en las células epiteliales de las glándulas salivales. La primoinfección durante la niñez se ha asociado principalmente con cuadros de exantema súbito, pitiriasis rosada y crisis febriles ${ }^{1,2}$.
En la población adulta tanto la primoinfección como la reactivación del virus se ha asociado a compromiso neurológico, desde encefalitis y meningitis a cuadros de mielitis, estos últimos casos pueden asociarse o no a polirradiculitis y compromiso de pares craneanos ${ }^{3-5}$. Estas manifestaciones neurológicas se han presentado en pacientes inmunocompetentes e inmunodeprimidos, correspondiendo algunos de ellos a reactivación de la infección previamente adquirida y en otros a infección primaria en la adultez $z^{1,2}$.

Comunicamos el caso clínico de un paciente adulto inmunocompetente que presentó una 
polirradiculitis aguda asociada a (VHH-7), sin mielitis ni otro compromiso del Sistema Nervioso Central (SNC).

\section{Caso clínico}

Paciente de 35 años de edad, sexo masculino, que fue hospitalizado en nuestra unidad de neurología, por un cuadro de 10 días de evolución caracterizado por dolor lumbar irradiado a la región glútea y a la cara posterior de ambos muslos. El paciente refería sensación de adormecimiento y parestesias en la región glútea bilateralmente en forma asimétrica, sin disfunción sexual ni trastorno esfinteriano. Al examen neurológico no presentaba compromiso de pares craneanos, fuerza normal tanto en extremidades superiores como inferiores, los reflejos osteotendíneos eran normales y simétricos, con respuesta plantar flexora bilateral. Presentaba hipoestesia al tacto $\mathrm{y}$ al dolor en la región glútea y perineal en forma asimétrica (mayor a izquierda) y en la cara lateral del pie izquierdo. Tacto rectal normal y reflejo anal presente. La resonancia nuclear magnética $(\mathrm{RMN})$ a nivel lumbosacro mostró leve engrosamiento de las raíces de la cauda equina y leve captación de gadolinio (Figura 1).

En el estudio de laboratorio se realizó hemograma, VHS, proteína C reactiva, enzima convertidora de angiotensina, con resultados normales.
Se realizó serología para VIH, Hepatitis B y C, Enfermedad de Lyme y Sifilis, que fueron negativas.

Se realizaron estudios de imágenes, tomografía axial computada de toráx, abdomen y pelvis que fueron normales y RMN Cerebral que no mostró lesiones intraparenquimatosas ni engrosamiento y/o captación en las meninges. Sin embargo, una RNM de médula a nivel torácico mostró leve captación de las raíces.

Se realizó punción lumbar con estudio de líquido cefalorraquídeo con 475 leucocitos por microlitro, proteínas $203 \mathrm{mg} / \mathrm{dl}$, glucosa $47 \mathrm{mg} /$ dl, Tinción Gram y cultivos negativos, Tinta China y antígenos para Criptococo Neoformans negativo y estudio de adenosin deaminasa negativo. El estudio con RPC fue negativo para Virus herpes simplex 1 y 2, citomegalovirus, Varicela Zoster, Epstein-Barr, Enterovirus (A-D, Coxsackie, Echovirus) y Virus Herpes 6. RPC fue positivo para VHH-7. Se realizó una segunda punción lumbar para evaluar la citometría de flujo que fue normal y se repitió estudio de RPC para VHH-7, con resultado positivo nuevamente.

Se realizó estudio de electromiografía y velocidad de conducción nerviosa 10 días después del inicio de los síntomas con resultado normal, incluyendo reflejo $\mathrm{H}$ en ambos gastrocnemios (raiz S1) y respuestas F.

El paciente recibió tratamiento sintomático para el dolor, fue evaluado por infectología no considerándose necesario el uso de tratamiento
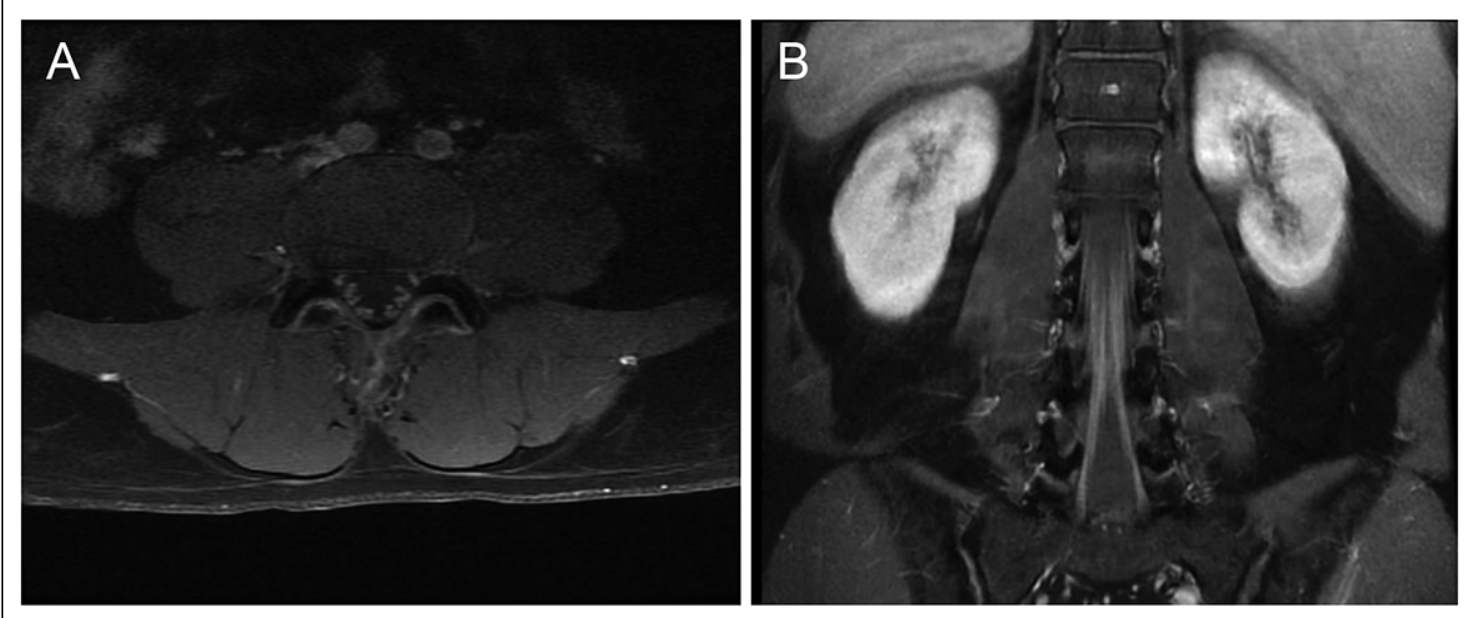

Figura 1. Resonancia magnética de columna lumbosacra con gadolinio. A. Corte axial B. Corte coronal, que muestra leve captación de contraste y engrosamiento de raíces. 
antiviral. Los síntomas se resolvieron después de 4 semanas, con examen neurológico completamente normal.

\section{Discusión}

La infección por VHH-7 puede manifestarse en diferentes etapas de la vida, con compromiso tanto del sistema nervioso central y del sistema nervioso periférico.

El rol patogénico de este virus fue reconocido en la década de los 90s, cuando se describió el primer caso de crisis febril y exantema súbito, asociado a compromiso neurológico severo ${ }^{6}$. Desde entonces, pequeñas series y reportes de casos, han presentado un amplio rango de manifestaciones neurológicas, incluyendo casos de meningitis leves autolimitadas, casos de encefalitis severas y mielitis con polirradiculoneuritis s.5,7,8 $^{3-}$.

En cultivos, el VHH-7 infecta linfocitos y tiene un efecto citopático, con células multinucleadas y aumentadas de tamaño ${ }^{1}$. Sin embargo, in vivo no está establecido si sus efectos patogénicos dependen de un mecanismo citopático o de un mecanismo autoinmune y tampoco cuales son los factores que explican el neurotropismo al cerebro/meninges en algunos pacientes y hacia raíces nerviosas en otros.

Nuestro paciente presentó un cuadro leve de polirradiculoneuritis aguda causada por $\mathrm{VHH}-7$, lo que es sustentado por el hallazgo de RPC positiva para este virus en dos muestras separadas de LCR, junto con la exclusión de otras causas de polirradiculoneuritis. No existió el antecedente de contacto con niños con exantema súbito previo al inicio del cuadro.

Una limitación en este caso es que el estudio serológico (IgM e IgG) no está disponible en nuestro centro ${ }^{2,5}$. Como consecuencia, no podemos establecer si en este paciente se trataría de una reactivación del virus o de una infección primaria tardía en la adultez.

Un caso único de infección primaria en la adultez en un paciente adulto inmunocompetente ha sido descrito, en este caso el paciente presento encefalitis, parálisis fláccida severa y compromiso ventilatorio ${ }^{5}$. Episodios de infección primaria también han sido descritos en tres adolescentes con presentación neurológica severa: 2 con encefalitis y uno con un síndrome de Guillian-Barré.
Posiblemente por analogía con otros virus herpes humanos, la primoinfección tardía puede causar presentaciones clínicas más severas que las infecciones primarias en la niñez ${ }^{9}$.

De relevancia para nuestro caso aparece la descripción en la literatura de un paciente adulto inmunocompetente con reactivación de la infección por VHH-7, quién presentó un cuadro moderado de mielitis asociado a compromiso de pares craneanos ${ }^{3}$. Otros 2 casos descritos, de meningitis autolimitada y de mielitis leve en pacientes adultos inmunocompetentes, presenataron buena respuesta a metilprednisolona y a ganciclovir, sin embargo en estos pacientes no se con contaba con serología para VHH-7 (IgM e IgG) ${ }^{4}$. Debido a que la mayoría de la población se infecta en la primera infancia, parece menos probable que estos 2 pacientes presentaran infección primaria en la adultez, tal como pareciera suceder en el caso de nuestro paciente.

La reactivación del VHH-7 también se ha asociado a enfermedades neurológicas en adultos inmunocomprometidos, como los que han recibido transplante de médula ósea (cuadro de mielitis con buena recuperación tras uso de metilprednisolona), transplante de células madre (encefalitis fatal) y un caso de un paciente infectado con VIH (mielitis leve $)^{10-12}$.

Con respecto al tratamiento, actualmente no existen guías clínicas que apoyen el uso de terapia antiviral en este grupo de pacientes. Sin embargo, en casos de encefalitis severa o de mielitis, algunos centros han tratado a sus pacientes con Aciclovir o Foscarnet endovenoso. Adicionalmente, algunos casos de mielitis han recibido dexametasona o metilprednisolona endovenosa e incluso inmunoglobulinas ${ }^{3-5,10}$.

En resumen, nuestro caso clínico muestra que el VHH-7 debe ser considerado como causa de polirradiculitis leve sin mielitis asociada en pacientes adultos inmunocompetentes.

\section{Referencias}

1. Black JB, Pellet PE. Human Herpesvirus 7. Rev Med Virol 1999; 9 (4): 245-62.

2. Ward KN. The natural history and laboratory diagnosis of human herpesviruses- 6 and -7 infections in the immunocompetent. J Clin Virol 2005; 32 (3): 183-93.

3. Mihara T, Mutoh T, Yoshikawa T, Shigeaki Y, Asano Y, 
Yamamoto H. Postinfectious Myeloradiculoneuropathy with Cranial Nerve Involvements Associated with Human Herpesvirus 7 Infection. Arch Neurol 2005; 62 (11): 1755-7.

4. Miranda M, Torres JP, Larrañaga C, Acuña G. Meningomyelitis associated with infection by human herpes 7. Report of two cases. Rev Med Chile 2011; 139: 158891.

5. Ward KN, Kalima P, MacLeod KM, Riordan T. Neuroinvasion During Delayed Primary HHV-7 Infection in an Immunocompetent Adult With Encephalitis and Flaccid Paralysis. J Med Virol 2002; 67 (4): 538-41.

6. Van den Berg JS, Van Zeijl JH, Rotteveel JJ, Melchers WJ, Gabreels FJ, Galama JM. Neuroinvasion by human herpesvirus type 7 in a case of exanthem subitum with severe neurologic manifestations. Neurology 1999; 52 (5): 1077-9.

7. Ward KN, Andrews NJ, Verity CM, Miller E, Ross EM. Human herpesviruses- 6 and -7 each cause significant neurological morbidity in Britain and Ireland. Arch Dis Child 2005; 90: 619-23.
8. Yoshikawa T, Ihira M, Suzuki K, Suga S, Matsubara T, Furukawa S, et al. Invasion by human herpes virus 6 and human herpes virus 7 of the central nervous system in patients with neurological signs and symptoms. Arch Dis Child 2000; 83 (2): 170-1.

9. Schwartz KL, Richardson SE, Ward KN, Donaldson C, MacGregor D, Banwell B, et al. Delayed Primary HHV-7 Infection and Neurologic Disease. Pediatrics 2014; 133 (6): 1541-7.

10. Escobar-Villalba A, Sainz de la Maza S, Pérez Torre P, Galán JC, Rodríguez-Domínguez M, Monreal E, et al. Acute mielitis by human herpes virus 7 in an HIV-infected patient. J Clin Virol 2016; 77: 63-5.

11. Ward K, White R, Mackinnon S, Hanna M. Human herpesvirus-7 infection of the CNS with acute myelitis in an adult bone marrow recipient. Bone Marrow Transplantation 2002; 30 (12): 983-5.

12. Chan PK, Chik KW, To KF, Li CK, Shing MM, Ng KC et al. Case report: human herpesvirus 7 associated fatal encephalitis in a peripheral blood stem cell transplant recipient. J Med Virol 2002; 66 (4): 493-6. 